\title{
Study of Brain Changes in Chronic Hepatic Encephalopathy by Using MR Imaging
}

\author{
Mohamed N El-Khashab ${ }^{1}$, Salama M ElGhonamy ${ }^{1}$, \\ Sherif M Galal ${ }^{1}$, Rasha I Salama ${ }^{1}$, Adel AL Sanour ${ }^{2}$ \\ ${ }^{I}$ Tropical Medicine Department, Faculty of Medicine, Zagazig University, Egypt \\ ${ }^{2}$ Radiology Department, Faculty of Medicine, Zagazig University, Egypt
}

Corresponding Author: Rasha I. Salama Mobile:

+201111655326

\section{E mail:}

salamarasha@yahoo.c om

Received: 12 /9 /2012

Accepted after

revision: $17 / 11 / 2012$

Key words:

Brain Changes; Hepatic

Encephalopathy; Magnetic resonance imaging; Manganese; Ammonia;Myoinsitol.
Background and study aim: Hepatic encephalopathy (HE) reflects a spectrum of neuro-psychiatric abnormalities. The aim of this study was to evaluate MR imaging of the brain in different grades of chronic $\mathrm{HE}$ and its correlation with clinical neurological abnormalities.

Patients and Methods: Sixty patients were included, 40 patients with chronic HE were divided into group I (GI) chronic persistent HE $(n=20)$, group II (GII) chronic relapsing $\mathrm{HE}(\mathrm{n}=20)$, another 20 patients with early compensated cirrhosis were chosen as control group (GIII), all patients were subjected to full clinical and laboratory investigations, estimation of serum ammonia and Manganese level in the blood, psychometric tests ,conventional MRI and MRS.

Results: A statistically significant increase in serum level of ammonia and manganese in GI $(162.1 \pm 55.8 \mu \mathrm{mol} / \mathrm{L}$, $3.35 \pm 0.34 \mathrm{ug} / \mathrm{dl}$, respectively) when compared to other groups. By conventional MRI there was statistically significant increased signal intensity of
$\mathrm{T} 1$ and $\mathrm{T} 2$ in group I compared with other groups. By MRS, there was statistical significant increase of glutamine in GI (3.9 $\pm 0.17 \mathrm{pp}$,) when compared to GII $(3.7 \pm 0.13 \mathrm{ppm}) \&$ GIII $(2.48 \pm 0.3 \mathrm{ppm})$ and significant reduction of both choline and myinstol among GI 1.98 $\pm 0.17 \mathrm{ppm}$, $2.19 \pm 0.20 \mathrm{ppm}$, when compared to GII $2.29 \pm 0.17 \mathrm{ppm}, 2.74 \pm 0.17 \mathrm{ppm}$ and GIII $2.59 \pm 0.019$ ppm, $3.15 \pm 0.11$ ppm . Moreover there was significant elevation in signal intensity of $\mathrm{T} 1$ corresponding to elevation of serum manganese $(2.91 \pm 0.6$ $\mathrm{ug} / \mathrm{dl}$ ) and significant elevation of signal intensity in T2 corresponding to elevation of serum ammonia $(116.9 \pm 49 \mu \mathrm{mol} / \mathrm{L})$, as well as highly significant positive correlation between serum ammonia and glutamine $(\mathrm{r}=0.86)$ and highly significant negative correlation between serum ammonia and choline $(\mathrm{r}=-0.42)$ and myinstol $(r=-0.47)$.

Conclusion: Changes in brain metabolites as detected by MRS may be sensitive markers for clinical monitoring of brain dysfunction and cognitive impairment in patient with chronic HE.

\section{INTRODUCTION}

Hepatic encephalopathy (HE) is a syndrome of neuropsychiatric dysfunction disease [1]. Hepatic encephalopathy is a common complication of advanced cirrhosis. Between one third to one half of hospitalizations for cirrhosis are related to HE. The frequency of hospitalization for $\mathrm{HE}$ has nearly doubled over the last decade, with lengths of stay between 5 and 7 days [2]. Patients with HE often have other manifestations of end-stage liver disease, such as ascites, jaundice, or gastrointestinal variceal bleeding. Hepatic encephalopathy can also develop as an isolated manifestation of decompensated cirrhosis. Hepatic encephalopathy usually signals advanced liver failure, and is often considered a clinical indication for evaluation for liver transplantation . HE may disable the patient from employment, driving and self-care, and require involvement of family or household members in the care of affected patients [3]. 
$\mathrm{HE}$ is clinically classified into three major categories, according to the underlying hepatic condition. Type A occurs in patients with acute liver failure. Type B occurs in patients without intrinsic liver disease but with large, noncirrhotic, portosystemic shunting. Type $\mathrm{C}$ is related to underlying cirrhosis with portosystemic shunting. Type $\mathrm{C}$ is the most common form, It can be divided to episodic or persistent[4].

MRI may help in diagnosis of hepatic encephalopathy, the most frequent conventional MR finding in hepatic encephalopathy is T1 weight image that gives high signal intensity of the basal ganglia caused mainly by deposition of manganese [5] and T2 caused by diffuse brain edema which seems to play an essential role in the pathogenesis of hepatic encephalopathy, which is believed to be related to the portosystemic shunt and increase level of ammonia, Changes found in conventaial MRI T1 and T2 have no quantitative relation to severity of HE [1,2]. MR spectroscopy (MRS) provides a measure of brain chemistry and metabolic changes which occurs in the astrocytes in patients with chronic liver cell failure which showing increase in glutaminel glutamate signal intensity and decrease myo-inosital and choline signal intensity to prevent massive cerebral edema. Changes seen on MRS imaging usually correlate with severity of hepatic encephalolpathy [6].

\section{PATIENTS AND METHODS}

This study was conducted in the Tropical Medicine and Radiology Departments, Zagazig University Hospitals from January 2009 to January 2012. The study included 60 patients with liver cirrhosis; 40 of them were chronic hepatic encephalopathy, (20 patients persistent hepatic encephalopathy with grade I-II after taking treatment and 20 patients relapsing hepatic encephalopathy, showed normal psychometric test), 20 of them early compensated cirrhosis as a control. The patients diagnosed for hepatic encephalopathy using psychometric tests and Grading of the symptoms of hepatic encephalopathy is performed according to the West Haven classification system.

All patients were divided into three groups:

\section{Group I: (Chronic persistent hepatic encephalopathy)}

It included twenty patients, 15 out of them were males, 5 patients were females, their ages ranged between 43-73 years.

Inclusion criteria for this group (GI)

Patients had changes in consciousness, intellectual function and behavior. Gait abnormalities and flapping tremors (grade I, II by west haven criteria) were included in this group.

\section{Group II (Chronic relapsing hepatic encephalopathy)}

It included twenty patients (14 patients were males, 6 patients were females) their ages ranged between 46-67 years.

Inclusion criteria for this group (GII)

Patients who had frequent episodes of acute HE and after examination. The patients were perfectly alert don't showed any sign of cognitive dysfunction and psuychometric test for all patients negative.

\section{Group III: (early compensated cirrhosis)}

It included twenty patients with no previous episodes of HE in these group, 16 were males and 4 were female their ages ranged between 42 67 years (G III).

\section{Exclusion Criteria:}

Patients with neuropathological evidence of trauma, tumor, Cerebrovascular accident or neurodegenerative disease (Alzheimer's disease or Parkinson diseases) will be excluded from the study regardless the presence of liver disorder.

\section{All patients were undergone:}

1- Full history taking and physical examination

2- Routine investigations: liver function tests, kidney function tests, prothrombine time, complete blood picture and pelvi-abdominal ultrasonogrophy

\section{3-Ammonia and manganese measurement}

(MN)

Fasting arterial blood samples were obtained from each patient to measure ammonia concentration $(\mu \mathrm{mol} / \mathrm{L}), \quad \mathrm{MN}$ concentration (ug/dl). 
4-Complete neuropsychological assessment by using psychometric tests (number connection test (NCT), circle connection test (CCT) [7].

\section{5) Magnetic resonance imaging}

Routine MRI was done for all patients. MR imaging consisted of transverse nonenhanced T1-weighted spin-echo and T2-weighted fast spin-echo sequences. The imaging parameters were 500/14 msec (repetition time msec/echo time msec), FOV: 230x $230 \mathrm{~mm}$ and a 2-minute acquisition time for T1-weighted imaging and 5000/86 msec (TR/TE msec), FOV: 230x 230 $\mathrm{mm}$ and a 3-minute acquisition time for T2-fast spin echo sequences. The section thickness was 5 $\mathrm{mm}$ with an intersection gap of $1 \mathrm{~mm}$.

${ }_{-}{ }^{1} H$ MR spectroscopy:

A-Localization and data acquisition: was achieved by acquiring three orthogonal. (sagittal, transverse, and coronal) gapless, HASTE sequences. Before recording the spectrum, the homogeneity of the magnetic field over the volume of interest was optimized by shimming. Suppression of water signal was performed by using three preceding Gaussian pulses (60- $\mathrm{Hz}$ bandwidth). Then multi-voxel PRESS technique using the following parameters TR: $1500 \mathrm{msec}$, TE: 30 msec and FOV: 230x 230mm was done.

B-Post processing: Spectral postprocessing consisted of zero filling Gaussian apodiztion for noise reduction with base line and phase correction.

C-Spectral analysis: Measurement was performed at following resonance myoinositol (mI) (3.5 ppm), glutamate or glutamine (Glx ) (3.75 ppm), creatine $(\mathrm{Cr}\}$ (3.03 ppm), Cho (3.22 ppm), and $\mathrm{N}$-acetylaspartate (NAA) (2.0 $\mathrm{ppm})$. Those metabolites were measured in the in deep white matter in the medial part of the occipital lobe, parietal. lobe and basal ganglionic regions. Metabolic ratios were calculated for $\mathrm{mI} / \mathrm{Cr}$, $\mathrm{Cho} / \mathrm{Cr}, \mathrm{Glx} / \mathrm{Cr}$ and $\mathrm{Na} / \mathrm{Cr}$ ratios in all our subjects.

\section{Statistical analysis}

Statistical were calculated using SPSS windows (version 10). Qualitative variables were expressed by means of frequency and percentiles, and were analyzed using the $\mathrm{X}^{2}$ test. Quantitative results are expressed as means \pm SD. Groups were compared by using paired t-test, ANOVA or thine Wilcoxon signed-rank test.

\section{RESULTS}

There were no significant difference in epidemiological and biochemical parameters among patients of the three groups of the study apart from statistical significant increase in serum bilrubin and reduction in serum albumin and prothrombine concentration in GI compared to other groups. Child score was high among patient in GI (11.5 \pm 1.54$)$ in comparison to group II (9.5 \pm 2.6$)$ and III $(5.5 \pm 0.5)$ with $\mathrm{P}<0.001$ (Table 1).

There was significant increased in signal intensity of T1 and T2 in group I compared with other groups with complete absence of signal among GIII with $(\mathrm{P}<0.001)$ (Table 2$)$.

Regarding MR spectroscopy in different groups, there was statistical significant increase of glutamine in GI (3.9 $\pm 0.17 \mathrm{ppm})$ when compared to GII $(3.7 \pm 0.1 \mathrm{ppm}) \&$ GIII $(2.48 \pm 0.3 \mathrm{ppm})$ with $\mathrm{P}<0.001)$ and significant reduction of both choline and myinstol among GI (1.98 $\pm 0.17 \mathrm{ppm})$ $(2.19 \pm 0.20 \mathrm{ppm})$ when compared to GII $(2.29 \pm 0.17$ ppm $) \quad(2.74 \pm 0.17)$ and GIII $(2.59 \pm 0.19) \quad(3.15 \pm 0.11) \quad$ respectively with $\mathrm{P}<0.001$ (Table 3, Figure 1\&2).

A significant high serum level of ammonia in GI $(162.1 \pm 55.8 \mu \mathrm{mol} / \mathrm{L})$ and high serum level of manganes in GI $(3.35 \pm 0.34 \mathrm{ug} / \mathrm{dl})$ was noticed when compared to other groups with $\mathrm{P}<0.001$ (Table 4).

Relation between Mn level in blood \& T1 signal image in hepatic patients, there was significant elevation in signal intensity in $\mathrm{T} 1$ in corresponding to elevation of level of $\mathrm{Mn}$ in blood $(2.91 \pm 0.6 \mathrm{ug} / \mathrm{dl})$ with $\mathrm{P}<0.001$ (Table 5).

A relation between ammonia level in blood and $\mathrm{T}_{2}$ signal intensity in hepatic patients, there was significant elevation in signal intensity in $\mathrm{T} 2$ in corresponding to elevation of level of ammonia in blood $(116.9 \pm 49 \mu \mathrm{mol} / \mathrm{L}) \mathrm{P}<0.001$ (Table 6).

A correlation between ammonia and chemical metabolities we found, MR spectroscopy revealed highly significant positive correlation between ammonia in blood and glutamine in the brain ( $\mathrm{r}=0.86, \mathrm{P}<0.001)$ as well as highly significant negative correlation between ammonia in blood and Choline $(\mathrm{r}=-0.42$, $\mathrm{P}<0.01)$ or Myinstol $(\mathrm{r}=-0.47, \mathrm{P}<0.001)$ in the brain (Table 7). 
Table (1): Clinical and laboratory findings in the studied groups.

\begin{tabular}{|c|c|c|c|c|}
\hline & $\begin{array}{c}\text { Chronic persistent } \\
\text { hepatic encephalopathy } \\
\text { (GI) } \\
\mathrm{N}=20\end{array}$ & $\begin{array}{c}\text { Chronic relapsing } \\
\text { hepatic encephalopathy } \\
\text { (GII) } \\
\mathrm{N}=20\end{array}$ & $\begin{array}{c}\text { Compensated early } \\
\text { cirrhosis (GIII) } \\
\mathrm{N}=20\end{array}$ & $\mathrm{P}$ \\
\hline $\begin{array}{l}\text { Male/Female } \\
\text { Mean age (years) }\end{array}$ & $\begin{array}{c}15 / 5 \\
56.1 \pm 8.5\end{array}$ & $\begin{array}{c}14 / 6 \\
54.1 \pm 4.9\end{array}$ & $\begin{array}{c}16 / 4 \\
53.1 \pm 9.2\end{array}$ & 0.46 \\
\hline T.bill (mg/dl) & $1.83 \pm 0.3$ & $1.4 \pm .3$ & $1.5 \pm 0.5$ & $0.002^{*}$ \\
\hline D.Bill. $(\mathrm{mg} / \mathrm{dl})$ & $0.76 \pm 0.1$ & $0.58 \pm 0.1$ & $0.9 \pm 0.2$ & $0.001 * *$ \\
\hline T.protein $(\mathrm{g} / \mathrm{dl})$ & $6.6 \pm 0.5$ & $6.9 \pm 0.3$ & $6.9 \pm 0.5$ & 0.25 \\
\hline S. albumin $(\mathrm{g} / \mathrm{dl})$ & $3.3 \pm 0.6$ & $3.2 \pm 0.5$ & $3.5 \pm 0.2$ & $0.001 * *$ \\
\hline Proth. Conc. & $50.6 \pm 8.95$ & $70.42 \pm 7.4$ & $90.2 \pm 4.1$ & $<0.05$ \\
\hline SGPT (IU/L) & $52.8 \pm 11$ & $45.5 \pm 12.1$ & $47.6 \pm 17.1$ & 0.22 \\
\hline SGOT (IU/L) & $58.5 \pm 14.6$ & $48.3 \pm 15.8$ & $50.5 \pm 16.9$ & 0.1 \\
\hline $\begin{array}{r}\text { Child score } \\
\text { A } 20 \\
\text { B } 14 \\
\text { C } 26 \\
\end{array}$ & $11.5 \pm 1.54$ & $9.5 \pm 2.6$ & $5.5 \pm 0.5$ & \\
\hline $\begin{array}{l}\text { Ultrasounds } \\
\text { Shrunken } \\
\text { Enlarged } \\
\text { Average }\end{array}$ & $\begin{array}{c}20 \\
0 \\
0\end{array}$ & $\begin{array}{c}4 \\
16 \\
0\end{array}$ & $\begin{array}{c}0 \\
0 \\
20\end{array}$ & $<0.001$ \\
\hline Ascitis & 20 & 16 & 0 & $<0.001$ \\
\hline Splenomegaly & 20 & 14 & 0 & $<0.001$ \\
\hline $\begin{array}{l}\text { Portosystemic } \\
\text { collateral }\end{array}$ & 20 & 9 & 0 & $<0.001$ \\
\hline
\end{tabular}

* Significant $\mathrm{P}<0.05$

** Highly significant $\mathrm{P}<0.001$

Table (2): $\mathrm{T}_{1}$ and $\mathrm{T}_{2}$ weighted images in different groups of patients.

\begin{tabular}{|c|c|c|c|c|c|c|c|c|}
\hline & \multicolumn{2}{|c|}{$\begin{array}{c}\text { GI } \\
(\mathrm{n}=20)\end{array}$} & \multicolumn{2}{|c|}{$\begin{array}{c}\text { GII } \\
(\mathrm{n}=20)\end{array}$} & \multicolumn{2}{|c|}{$\begin{array}{c}\text { GIII } \\
(\mathrm{n}=20)\end{array}$} & $X^{2}$ & $\mathrm{P}$ \\
\hline \begin{tabular}{|ll}
$\mathrm{T}_{1}$ & \\
& Positive \\
& Negative \\
\end{tabular} & $\begin{array}{c}20 \\
0\end{array}$ & $\begin{array}{c}100.0 \\
0.0\end{array}$ & $\begin{array}{c}13 \\
7\end{array}$ & $\begin{array}{l}65.0 \\
35.0\end{array}$ & $\begin{array}{c}0 \\
20\end{array}$ & $\begin{array}{c}0.0 \\
100.0\end{array}$ & 41.6 & $<0.001$ \\
\hline \begin{tabular}{|ll}
$\mathrm{T}_{2}$ & \\
& Positive \\
& Negative
\end{tabular} & $\begin{array}{c}13 \\
7\end{array}$ & $\begin{array}{l}65.0 \\
35.0\end{array}$ & $\begin{array}{c}7 \\
13\end{array}$ & $\begin{array}{l}30.0 \\
65.0\end{array}$ & $\begin{array}{c}0 \\
20\end{array}$ & $\begin{array}{c}0.0 \\
100.0\end{array}$ & 19.05 & $<0.001$ \\
\hline
\end{tabular}

$\mathrm{G}=$ group

Table (3): MR spectroscopy metabolite and ratios in different groups.

\begin{tabular}{|c|c|c|c|c|}
\hline & $\begin{array}{c}\text { Chronic persistent } \\
\text { hepatic encephalopathy } \\
\text { (GI) } \\
\mathrm{N}=20\end{array}$ & $\begin{array}{c}\text { Chronic relapsing } \\
\text { hepatic encephalopathy } \\
\text { (GII) } \\
\mathrm{N}=20\end{array}$ & $\begin{array}{l}\text { Compensated early } \\
\text { cirrhosis (GIII) } \\
\qquad \mathrm{N}=20\end{array}$ & $\mathrm{P}$ \\
\hline $\begin{array}{l}\text { Glutamine/ } \\
\text { Glx/Cr }\end{array}$ & $\begin{array}{c}3.9 \pm 0.17 \\
1.85 \pm 0.59 \\
\end{array}$ & $\begin{array}{c}3.7 \pm 0.13 \\
1.34 \pm 0.49 \\
\end{array}$ & $\begin{array}{c}2.48 \pm 0.3 \\
1.18 \pm 0.50 \\
\end{array}$ & $<0.001$ \\
\hline \begin{tabular}{|l|} 
Choline \\
Cho/Cr
\end{tabular} & $\begin{array}{l}1.98 \pm 0.17 \\
0.68 \pm 0.10\end{array}$ & $\begin{array}{l}2.29 \pm 0.17 \\
0.80 \pm 0.12\end{array}$ & $\begin{array}{l}2.59 \pm 0.19 \\
0.91 \pm 0.11\end{array}$ & $<0.001$ \\
\hline $\begin{array}{l}\text { Mynstol } \\
\mathrm{Mi} / \mathrm{Cr}\end{array}$ & $\begin{array}{l}2.19 \pm 0.20 \\
0.32 \pm 0.12\end{array}$ & $\begin{array}{l}2.74 \pm 0.17 \\
0.75 \pm 0.16\end{array}$ & $\begin{array}{l}3.15 \pm 0.11 \\
0.97 \pm 0.13\end{array}$ & $<0.001$ \\
\hline
\end{tabular}

Measurements in ppm, G=group. 

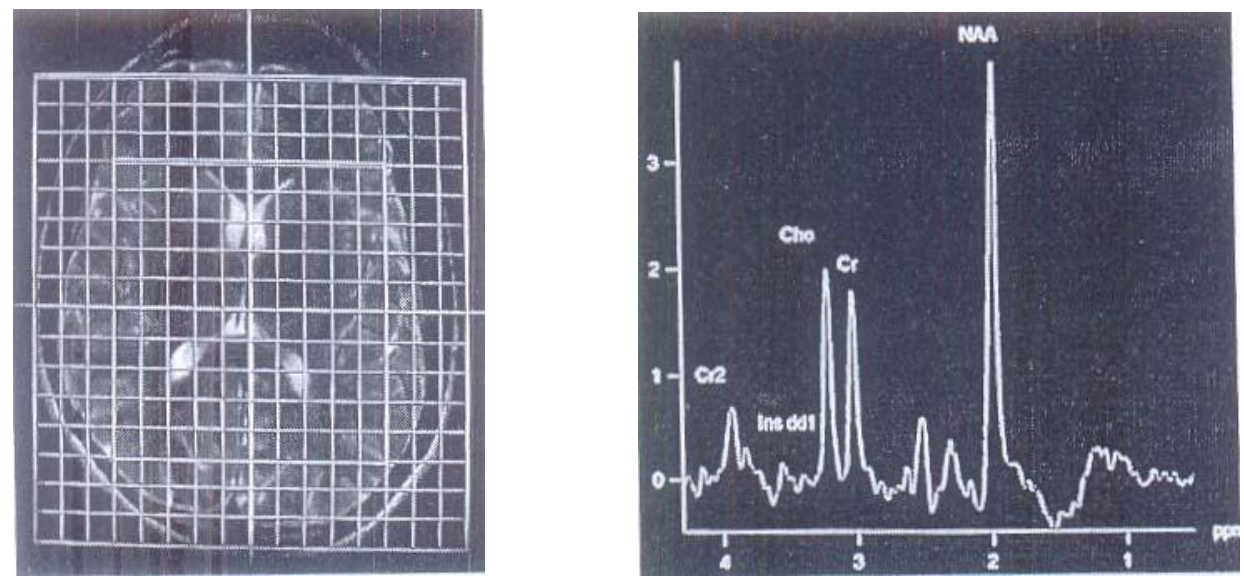

Figure (1): $\quad{ }^{1} \mathrm{H}$-spectroscopy in control subject (early cirrhosis). VOI is placed in the white matter of right occipital lobe showed the normal resonance of myo-inositol (mI), choline (Cho), creatine $(\mathrm{Cr})$ and $\mathrm{N}$-acetylaspartate (NAA).
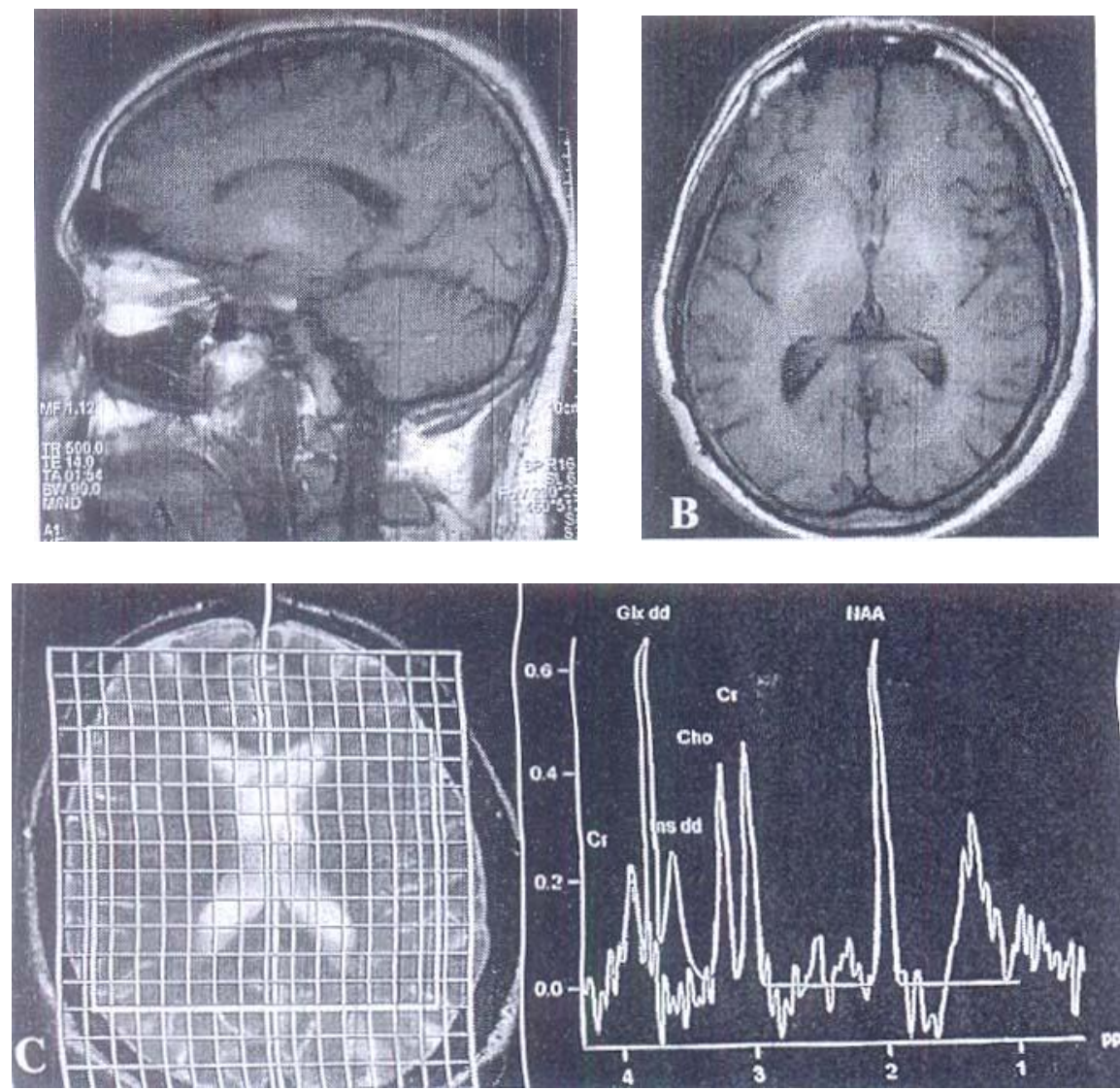

Figure (2): $\quad$ MR imaging and MR ${ }^{1} \mathrm{H}$-spectroscopic finding in patient with liver cirrhosis and overt hepatic encephalopathy. (A and B): Sagittal and axial T1 WI (TR/TE; 500/14 msec) showed bright intensity in the basal ganglionic region. (C) CSI ${ }^{1} \mathrm{H}$-spectroscopy, VOI is placed in the white matter of the right parietal region, showed marked increased in glutamate or glutamine (Glx) and decrease in Mi and Cho compared to the healthy control subject. No change as regard the $\mathrm{N}$-acetylaspartate. 
Table (4): Serum level of ammonia and manganes in different groups of patients.

\begin{tabular}{|c|c|c|c|c|c|}
\hline & GI & GII & GIII & F & P \\
\hline Ammonia $(\mu \mathrm{mol} / \mathrm{L})$ & & & & & \\
$\bar{X} \mathrm{SD}$ & $162.1 \pm 55.8$ & $95.8 \pm 12.7$ & $51.2 \pm 9.9$ & 56.2 & $<0.001$ \\
Range & $85-220$ & $75-115$ & $33-65$ & & \\
\hline Manganes (ug/dl) & & & & & \\
XSD & $3.35 \pm 0.34$ & $2 \pm 0.6$ & $1.3 \pm 0.16$ & 45.8 & $<0.001$ \\
Range & $2.7-3.9$ & $0.7-2.8$ & $0.9-1.5$ & 45.8 \\
\hline
\end{tabular}

$\mathrm{G}=$ group

Table (5): Relation between Mn level in blood \& T1 signal image in hepatic patients.

\begin{tabular}{|c|c|c|c|}
\hline $\mathrm{T}_{1}$ & $\overline{\mathrm{Mn}}(\mathrm{ug} / \mathrm{dl})$ & $\mathrm{T}$ & $\mathrm{P}$ \\
\hline Positive & $2.91 \pm 0.6(1.7-3.9)$ & \multirow{2}{*}{8.3} & $<0.001$ \\
\hline Negative & $1.6 \pm 0.6(0.7-2.8)$ & & $<.3$ \\
\hline
\end{tabular}

Table (6): Relation between ammonia level in blood and $\mathrm{T}_{2}$ signal intensity in hepatic patients.

\begin{tabular}{|c|c|c|c|}
\hline $\mathrm{T}_{2}$ & $\begin{array}{c}\text { Ammonia( } \mu \text { mol/L) } \\
\overline{\mathrm{XSSD}}(\text { Range })\end{array}$ & $\mathrm{T}$ & $\mathrm{P}$ \\
\hline Positive & $71.1 \pm 21.9(33-105)$ & \multirow{2}{*}{10.4} & $<0.001$ \\
\hline Negative & $116.9 \pm 49(75-220)$ & & $<$ \\
\hline
\end{tabular}

Table (7): Correlation between ammonia \& other parameter.

\begin{tabular}{|l|c|c|c|}
\hline & $\mathrm{r}$ & $\mathrm{P}$ & \\
\hline Glutamine $(\mathrm{ppm})$ & 0.86 & $<0.001$ & $\mathrm{HS}$ \\
\hline Choline $(\mathrm{ppm})$ & -0.42 & $<0.001$ & HS \\
\hline Myinstol $(\mathrm{ppm})$ & -0.47 & $<0.001$ & HS \\
\hline
\end{tabular}

\section{DISCUSSION}

Hepatic encephalopathy includes a spectrum of neuropsychiatric abnormalities occurring in patients with liver dysfunction. Most cases are associated with cirrhosis and portal hypertension or portal-systemic shunts, but the condition can also be seen in patients with acute liver failure and not associated with intrinsic hepatocellualr disease [8]. Chronic HE can be subclassified into relapsing $\mathrm{HE}$ and persistent HE. Relapsing HE manifests as frequent episodes of acute HE that may be due to precipitating factors, these patients can be perfectly alert and don't show any sign of cognitive dysfunction. However, a careful neurologic examination and neuropsychological tests may reveal subtle abnormalities. Persistent HE refers to manifestations that do not reverse despite adequate treatment [3].

The liver and brain interact in numerous ways to ensure normal brain function. By using MR imaging for diagnosis there was increase in substances that under normal circumstances are efficiently metabolized by the liver. Classic MR imaging abnormalities include on $\mathrm{T}_{1}$-weighted images due to high signal intensity in the globus pallidum caused by increased tissue concentrations of manganese, as well as elevated glutamine/glutamate peak coupled with decreased myoinositol and choline signals on proton MR spectroscopy representing disturbances in cell-volume homeostasis secondary to brain hyperammonemia to protect astrocyte [9].

In the present study we found high statistically significant increase in serum level of ammonia and manganese in chronic persistent hepatic encephalopathy when compared to other groups. So serum ammonia and manganese increase with the degree of brain affection these results agreed with that reported by Butterworth et al. [10] and Rose et al. [11].

Our results showed significant increase signal intensity of $T_{1}$ and $T_{2}$ in chronic persistent HE compared to chronic relapsing $\mathrm{HE}$ that agreed with Weissenborn et al. [12], also significant elevation of signal intensity of $\mathrm{T} 2$ and $\mathrm{T} 1$ corresponding to elevation of serum level of 
ammonia and manganese respectively were detected .This agreed with Rovira et al. [3] who found that liver transplantationt provides normalization of both the MRI abnormalities and Mn levels seem to confirm the suspicion of manganese being the responsible agent for the hyperintensity of T1-weighted images .

Signal alterations in T2-weighted MR images in chronic $\mathrm{HE}$ are less frequently reported. However, there have been studies showing T2 hyperintensity along the cortico-spinal tract in the brain of cirrhotic patients which were reversed after liver transplantation using the fastfluid attenuation inversion recovery (FLAIR) sequence [13].

Moreover we found MRS that showed different metabolic changes of the brain in these patients, significant increase in glutamine and significant reduction in choline and myomositol in patients with chronic persistent HE compared to other groups .Our result agreed with those of Ross et al. [14]; Kreis et al. [15] and Rovira et al. [3] and disagree with this study Kostter [16] and Lee et al. [17] in which no difference in 1H-MR spectroscopy finding between patients with and without HE.

Correlation between ammonia and chemical metabolites found in MR spectroscopy revealed highly significant positive correlation between ammonia in blood and glutamine in the brain as well as highly significant negative correlation between ammonia in blood and Choline or Myinstol in the brain were seen .

In chronic hepatic encephalopathy decreased urea cycle activity result in increased level of ammonia with increase synthesis of cerebral glutamine in astrocyte. The effects of increased intracellular glutamate include a reduction in $\mathrm{K}$ uptake an increased in $\mathrm{Cl}$ uptake which leads to reduction in Myinstol and Choline to prevent more brain edema and astrocyte damage [18].

The current study showed that level of ammonia and manganese correlate with MRI images and with MRS metabolites moreover this study showed significant difference in different grades of hepatic encephalopathy.

Diagnosis of patients of chronic persistent hepatic encephalopathy can be easily done by measuring the chemical parameters so by collectively, MRI, MRS, and estimation of serum manganese and ammonia can told us to prioritize patients of chronic hepatic encephalopathy for liver transplantation.

Funding: Non .

Conflicts of interest: The authors declare that there is no conflict of interest.

Ethical approval: The protocol of the study was approved by the committee of Faculty of Medicine, Zagazig University. Where the procedures followed were in accordance with the ethical standards of the responsible committee on human experimentation (institutional or regional) and with the Helsinki Declaration of 1964 Informed consents were obtained from all patients.

\section{REFERENCES}

1- Zeneroli M, Cioni G, Vezelli C, Veutura E, Crisi G. Globus pallidus alterations and brain atrophy in liver cirrhosis patients with encephalopathy. A MR imaging study. Magn Reson Imaging 1991; 9: 295-302.

2- Pujol A, Pujol J, Graus F, Rimola A, Peri J, Mercader J, et al. Hyperintensive globus pallidus on T1-weighted MRI in cirrhotic patients is associated with severity of liver failure. Neurology 1993; 43: 65-9.

3- Rovira A, Alonso J, Cordoba J. MR imaging findings in hepatic encephalopathy. Am J Neroradiol 2008;29:1612-21

4- Jin Y, Yue Y, he C, Yin N, Yang L. The cerebral MRI findings in patients with acquired heopatocerebral degeneration. Chinese Journal of Radiology 2000; 34: 841-843.

5- Cordoba J, Sanpedro F, Alonso J, Rovira K. H-1 magnetic resonance in the study of hepatic encephalopathy in humans. Metab Brain Dis 2002; 17: 415-429.

6- Naegele T, Grodd W, Viebahn R, Seeger U, Klose U, Seitz D, et al. MR imaging and (1) H spectroscopy of brain metabolites in hepatic encephalopathy: time course of renormalization after liver transplantation. Radiology 2000; 216: 683-691.

7- El-Amin H.M. Circle connection test. M. Sc. Thesis. Psychology. A method for measuring cerebral dysfunction in patients with chronic liver disease. Zagazig university 1985; 109.

8- Ferenci P, Lockwood A, Mullen K, Tarter R, Weissenborn K, Blei AT. Hepatic encephalopathy: definition, nomenclature, diagnosis, and quantification-final report of working party at the $11^{\text {th }}$ World Congresses of gastroenterology Vienna. Hepatology 2002; 35: 716-21. 
9- Krieger S, Jauss M, Jansen O, Theilmann L, Geissler M, Krieger D. Neurosychiatric profile and hyperintensive globus pallidus on T1weighted magnetic resonance images in liver cirrhosis. Gastrointerology 1996; 111: 147-55.

10- Butterworth RF, Giguere JF, Michaud J, Lavoie J, Layrargues EP. Ammonia: key factor in the pathogenesis of hepatic encephalopathy. Neurochem Pathol 1987; 6: 1-12.

11- Rose C, Butterworth RF, Zayed J, Normandin L, Todd K, Michalak A, et al. manganese deposition in basal ganglia structures results from both portal-systemic shunting and liver dysfunction. Gastroenterology 1999; 117: 640-644.

12- Weissenborn K, Ehrenheim C, Hori A, Kubicka $\mathrm{S}$, Manns MP. Pallidal lesions in patients with liver cirrhosis: Clinical and MRI evaluation. Metab Brain Dis 1995; 10: 219-231.

13- Cordoba J, Blei AT. hepatic encephalopathy. In: Shiff ER, Sorrell MF, Moddrey WC, eds. Shiffs Diseases of the liver. Philadelphia, Lippincott Williams \& Wilkins 2003, 595-623
14- Ross BD, Jacobson S, Villamil F, Korula J, Kreis R, Ernst T, et al. Subclinical hepatic encephalopathy: proton MR spectroscopic abnormalities. Radiology 1994; 193: 457-463.

15- Kreis R, Ross BD, Farrow NA, Ackerman Z. Metabolic disorders of the brain in chronic hepatic encephalopathy detected with H-1 MR spectroscopy. Radiology 1992; 182: 19-27.

16- Kostter H. Proton magnetic resonance spectroscopy in portal-systemic encephalopathy. Metab Brain Dis 1998; 13: 291-301.

17- Lee JH, Seo DW, lee Y, Kim ST, Mun CW, Lim THet al. Proton magnetic resonance spectroscopy (1H-MRS) findings for the brain in patients with liver cirrhosis reflect the hepatic functional reserve. Am J Gastroenterol 1999; 94: 2206-13.

18- Norenberg M, Bender A. Astrocyte swelling in liver failure: role of glutamine and benzoidiazepines. Acta Neurochir Suppl 1994 (Wien); 60: 24-27. 